http://dx.doi.org/10.5209/rev_ARAB.2011.n30.37837

ÁREA ABIERTA N 30. NOVIEMBRE 2011

Referencia: AA30.1111.151

"JOSÉ JARA: UN APOCALÍPTICO EN EL CINE, UN REFUGIADO EN LA UNIVERSIDAD" AUTOR: Dr. Luis DELTELL ESCOLAR. Universidad Complutense de Madrid.

\title{
José Jara: \\ Un apocalíptico en el cine, un refugiado en la universidad
}

\author{
José Jara: \\ An Apocalyptic Filmaker, \\ a Refugee at the University
}




\begin{abstract}
Resumen:
Este artículo es un análisis de la obra cinematográfica de José Jara (también conocido como José Royo Jara y John O'Hara). Se presenta la originalidad temática y estética de sus primeras obras: Las cuatro novias de Augusto Pérez (1976), la única adaptación cinematográfica para sala de cine de "Niebla", la novela de Miguel de Unamuno, y El transexual (1977), que es la primera película que mezcla el documental y la ficción sobre el tema de la transexualidad en el cine español.

También se estudian su última etapa en el cine erótico, en el cine industrial así como su trabajo como escritor y docente de dirección cinematográfica.
\end{abstract}

Palabras clave: Adaptación, transexualidad, José Jara, Unamuno, cine español.

\title{
Abstract:
}

This paper analyzes the films of José Jara (also known as José Royo Jara and John O'Hara). This research describes the thematic and aesthetic originality of his early works: Las cuatro novias de Augusto Pérez (1976), the only one film adaptation of "Niebla" (Miguel de Unamuno) to cinema theater; And El transsexual (1977), which is the first Spanish film that mixes documentary (non fiction) and fiction film about the transsexualism. Also this paper reviews the last works of José Jara: an erotic film, industrial shorts movies, his novel and his activity as Film Directing professor.

Keywords: Adaptation, transsexualism, José Jara, Unamuno, Spanish cinema.

\section{Intoducción}

Adentrarse en el cine español es uno de los trabajos más escurridizos que se puede plantear un investigador. Cuando nos alejamos del sendero parapetado por la celebridad o por el éxito de crítica, los directores, las películas y los largometrajes españoles se oscurecen y se vuelven misteriosos. A nadie le extraña que no se conserve documentación sobre ciertos autores, títulos u obras. Con una sorprendente frecuencia se descubre que de muchas películas no sólo no se puede encontrar ningún legajo oficial, sino que incluso las propias bobinas se han perdido para siempre. No hace falta remontarse a los remotos años del período silente, pues esto ocurre también con el cine de los años 70 y 80. Los autores menos conocidos parecen condenados, como sus películas, a encogerse, retorcerse y morir bajo el síndrome del vinagre en la Filmoteca Española. La obra cinematográfica de José Jara se sitúa peligrosamente en esa posición, algunos de sus títulos se almacenan en un estado de conservación desgraciadamente lamentable y otros ya han desaparecido para siempre.

Cuando el historiador de cine se plantea el estudio de un cineasta español suele encontrar ciertas vías para entenderlo y situarlo: de una forma habitual, muchos de los directores que comenzaron en los sesenta y setenta tuvieron una relación directa o indirecta con la Escuela Oficial de Cine (EOC, antiguo Instituto de Investigación y Experiencias Cinematográficas), con los estudios de la televisión pública (TVE) o con alguna de las grandes sagas familiares de la industria nacional. Así, el investigador puede deshilar y encontrar información en anuarios, realizar entrevistas a compañeros y familiares del cineasta o rastrear en los archivos de TVE y de la 
EOC. Sin embargo, José Jara no cumple ninguno de estos perfiles: ni se formó en la EOC ni colaboró de manera funcionarial en TVE ni siquiera pertenecía a una de las grandes familias de cineastas; es un raris avis.

La singularidad de José Jara se debe a su formación autodidacta, a su vida nómada en el extranjero, a su relación con las nuevas olas, a su compresión de Europa como un único lugar (muy acorde al espíritu de Stefan Zweig) y, por supuesto, a su absoluta independencia de toda industria, escuela, movimiento o ideología. A diferencia del prototípico realizador español sufragáneo de las ayudas oficiales, que aguarda impaciente e inquieto cualquiera de los cambios en las normativas de la Dirección General de Cinematografía o en los otros entes públicos, José Jara vivió como un artista ácrata fuera de grupo, colegio o colectivo. Su actitud libérrima le llevó hasta a rehusar y alejarse de la codiciada popularidad y así como un rara avis anónimo firmó, o aceptó que otros firmaran, sus trabajos fílmicos y sus textos de la formas más dispares: José Royo Jara, José Royo, José Jara, José Lara', John O’Hara... o, simplemente, Pepe Royo.

La hipótesis de este trabajo es que la obra de José Jara se muestra con una autoría y personalidad destacables pero precisamente su singularidad y su independencia de los cánones oficiales le condenaron y le alejaron de la industria, de las ayudas oficiales y al final terminaron expulsándolo del sistema. Lo que se pretende es mostrar cómo José Jara es, por su originalidad, un ejemplo interesante del cine de autor de la transición española.

El objetivo principal del trabajo es mostrar la autoría y el estilo de José Jara. Por ese motivo analizaremos y estudiaremos sus diversos trabajos audiovisuales (Ginebra [1964-65], Homo Hominis [1971], Las cuatro novias de Augusto Pérez [1976], El transexual [1977], El oasis de las chicas perdidas [1981] y los cortometrajes de publicidad industrial para la productora audiovisual Majesa) y sus textos literarios ("Mater Amantíssima").

Ante la complejidad y la falta de documentación sobre el director estudiado se propone una metodología histórica, basada en el análisis de textos oficiales (consultados del Archivo General de la Administración -AGA-, Archivo de Televisión Española, Archivo de la Filmoteca Española, Biblioteca Española, así como diversas hemerotecas nacionales e internacionales), visionado de sus productos audiovisuales (siguiendo el modelo de análisis cuantitativo propuesto por David Bordwell, Janet Staiger y Kristin Thopson²) y la realización de una entrevista a José Royo Jara ${ }^{3}$ (siguiendo el modelo de investigación propuesto por el profesor Emilio C. García Fernández ${ }^{4}$ ).

\section{Formación: Ginebra y Homo Hominis}

José Royo Jara nació en Casas Ibáñez (Albacete) en 1940 y estudió con los jesuitas. Ni su familia ni sus conocidos se relacionaban con la industria cinematográfica. Su vida se situaba plenamente en la periferia del cine. Sin embargo, uno de los recuerdos infantiles es, sin quererlo, plenamente fílmico y casi, como lo serán sus primeras obras, experimental:

"Casi tengo que decir que mis primeras películas las vi de espaldas a la pantalla, ya que yo estudiaba en los jesuitas y en la sesión de cine de los domingos era muy frecuente que te castigaran de esa manera, con lo que vi muchas películas de espaldas y sólo las recuerdo por los diálogos" 5 .

En su etapa universitaria, el cine sigue sin ser una de sus grandes aspiraciones o anhelos profesionales. Su alma máter fue la Universidad Complutense de Madrid, donde se licenció en Derecho y se especializó en el Derecho Internacional. Cuando en 1962 finaliza sus estudios, se encuentra cansado y hastiado de la situación política española, abandona y huye de la España de Franco. José Jara lo explicaba así en 1978: "Al terminar la carrera, comprendí que no había ninguna salida, ni política ni profesional con lo cual decidí marcharme al extranjero"6.

Viaja como lector de español a Inglaterra y trabaja en varios institutos ingleses como enseñante ${ }^{7}$ de lengua castellana. Realiza diversas estancias por Europa y trabaja en un sinfín de actividades, quehaceres y ocupaciones. En 1980, en la contraportada de su libro "Mater amantissima" la editorial Tusquets editó una pequeña biografía divertida y disparatada en la que entre otros oficios escribía que José Jara había sido "embalsamador en Vaduz"8. Aunque esta biografía se ha repetido en los libros, en los artículos de

\footnotetext{
${ }^{1}$ El nombre de José "Lara" pude tratarse de una errata copiada y repetida por error en varios textos. Lo cierto es que como veremos se produce sobre todo en los trabajos de género que estudian o analizan El transexual (1977) y de un modo u otro cuestionan la autoría del director.

2 BORDWELL, David, STAIGER, Janet y THOMPSON, Kristin: El cine clásico de Hollywood. Paidós, Barcelona, 1997.

${ }^{3}$ La entrevista realizada a José Royo Jara será donada al Archivo de la Biblioteca de la Facultad de Ciencias de la Información.

${ }^{4}$ GARCÍA FERNÁNDEZ, Emilio C. (Coordinador): Memoria viva del cine español. Cuerdos de la Academia, Madrid, 1998.

${ }^{5}$ GREGORI, Antonio: El cine español según sus directores. Cátedra, Madrid, 2009. Pág. 877.

${ }^{6}$ HERNÁNDEZ LES, Juan y GATO, Miguel: El cine de autor. Castellote Editor, Madrid, 1978. Pág. 315.

${ }^{7}$ Este lectorado de español, se trata de un programa de los años sesenta y setenta con institutos británicos. No hay que confundirlos con los lectorados de español de las universidades anglosajonas y de las universidades galas de los mismos años y que aún se mantienen en la actualidad.

${ }^{8}$ Aparece en la solapa del libro JARA, José: Mater Amantíssima. Sonrisa Vertical, Tusquets Editores, Barcelona, 1980.
} 
investigación, en las páginas web de cine y se ha traducido a varios idiomas no es más que un enredo o una ficción más de un creador?. José Jara se inventó este trabajo como homenaje al entonces polémico y famoso doctor aragonés Pedro Ara, que había publicado contemporáneamente un libro explicando cómo había sido el misterioso embalsamiento de Eva Perón ${ }^{10}$.

A principios de los sesenta consigue una beca de doctorado en el prestigioso Instituto Universitario de Altos Estudios Internacionales (Institut de Hautes Études Internationales, IUHEI) ${ }^{11}$ adscrito a la Universidad de Ginebra. Esta estancia impulsó su verdadero despertar cinematográfico, pues allí se encontró con las posibilidades culturales y económicas que no había disfrutado ni en España ni en Inglaterra: Por un lado disponía, como estudiante del IUHEI, de la biblioteca internacional de la ONU, en donde tomó prestado todos libros que pudo sobre cine; por otro la posición fronteriza de Ginebra le permitió gozar de una extraordinaria libertad como espectador cinematográfico:

"... veía mucho cine en Suiza y, curiosamente, había muchas películas censuradas en Francia que se veían sin problemas en Suiza y, al contrario, películas prohibidas en Suiza que se podían ver en Francia. Había un pueblecito próximo a la frontera franco-suiza, que se aproximaba a lo que significaba para España Perpiñán o Biarritiz, donde podía verse mucho cine"12.

Por tanto, su gusto cinematográfico se forjó en el momento de consolidación de la Nouvelle Vague (Nueva Ola). Precisamente una de las películas a las que se refiere sin mencionar en la respuesta anterior será El soldadito (Le petit soldat, 1963) de Jean-Luc Godard, rodada en Francia en 1960 que fue prohibida en el país galo y que se estrenó de forma escandalosa en Suiza. La influencia de Godard y de la Nueva Ola francesa será la base de donde mana primer planteamiento estético de José Jara. La idea de ruptura con lo clásico, de choque con lo convencional y el enfrentamiento social y político con lo establecido son a la vez constantes del cine de Godard, de las nuevas olas y, por supuesto, del de Jara'13.

En su etapa en Ginebra contacta con los periodistas y críticos del Journal de Genève ${ }^{14}$. Este diario se situaba en la línea más liberal de la sociedad suiza. Gracias a ellos conoce a Alain Tanner que había realizado ya sus primeros documentales y largometrajes de ficción.

En 1964, José Jara rueda su primera película Genève (Ginebra) se trata de un cortometraje documental sobre la ciudad. Rodado de forma experimental se acercaba en su planteamiento a la estética de los poemas urbanos de la década de los veinte. Aunque se encuentran algunas referencias sobre este documental en libros, lo cierto es que no se conserva ninguna copia del mismo ni en la Filmoteca Española ni en Swiss Films. Tampoco se ha encontrado ni la fecha de estreno ni publicidad alguna del mismo en los diarios de Ginebra. Por lo tanto, la única fuente que nos queda para el conocimiento de la obra son las palabras de su autor15.

"Se trataba de un pieza experimental, yo intentaba probar cosas, quería hacer cine sin conocer muy bien su mecánica. Nadie me había explicado que era el eje, el raccord, la continuidad... lo que yo hice fue descubrirlo todo con la práctica. Además, intencionalmente quería ser vanguardista romper con las películas de siempre, no quería contar una historia sino simplemente mostrar la ciudad"16.

Si aceptamos las palabras de su autor, Genève se posicionaba en la línea más experimental y rupturista de la nueva estética cinematográfica. Carecía de trama narrativa clara o explicativa y su argumento se sustentaba tan sólo en el tema: el retrato de la urbe como un espacio onírico. En cierto modo, se debía tratar de un homenaje o poema fílmico a la urbe suiza, realizado por un emigrante agradecido por las posibilidades que la ciudad le había ofrecido y reportado.

Los estudios del IUHEI dejaron de interesarle y decidió centrarse sólo en su formación cinematográfica. Alain Tanner le recomienda viajar a Francia o, a pesar de la dictadura, regresar a España; cualquier cosa, pero huir de Suiza, un "país subdesarrollado cinematográficamente"17. Jara se resiste a volver a su patria y piensa en

\footnotetext{
${ }^{9}$ Entre las páginas que repiten dicha información se encuentra la propia de los editores: www.tusquetseditores/autores/josejara ${ }^{10}$ ARA, Pedro: El caso de Eva Perón. CVS ediciones, Madrid, 1974.

${ }^{11}$ El IUHEI se fundó en 1927 y resultaba ser un corolario de las iniciativas de la Sociedad de Naciones, creada en 1920 en Ginebra. Por su carácter internacional se escogieron como idiomas oficiales el inglés y el francés. Se dividieron sus estudios en cuatro grandes áreas temáticas: Derecho Internacional, Historia Política, Ciencias Políticas y Economía. Entre sus egresados más celebérrimos se encuentran: Kofi Anam, Enrique I de Luxemburgo...

En 2007 el IUHEI sufrió una profunda renovación y en el 2008, adherido al Institut Univeristaire d'etudes du développement (Instituto Universitario de Estudios de Desarrollo), se reabrió como Insititut du Hautes Études Internationales et du Développement (Instituto de Altos Estudios Internacionales y de Desarrollo) conocido por el acrónimo IHEID.

${ }^{12}$ GREGORI, Antonio: Op. Cit. Pág. 878.

${ }^{13}$ Godard seguirá siendo uno de los autores más citados por José Jará. Así es uno de los cineastas que utilizará para explicar su programa de Dirección Cinematográfica en la Facultad de Ciencias de la Información en la UCM.

${ }^{14}$ El Journal de Genève se fusionó en 1987 con otros diarios ginebrinos creando el nuevo periódico Le temps. El archivo histórico del periódico se encuentra en la actualidad conservado y catalogado en Le temps.

${ }^{15} \mathrm{Al}$ no existir ni copia ni estreno ni ficha oficial conocida no se puede confeccionar una descripción de los autores o creadores del mismo.

16 Entrevista realizada por el autor del artículo al profesor José Royo Jara en diciembre de 2010 en la Facultad de Ciencias de la Información de la UCM.

${ }^{17}$ HERNÁNDEZ LES, Juan y GATO, Miguel: Op. Cit. Pág. 316.
} 
trabajar en Francia pero la industria y la televisión galas le resultan inaccesibles y hostiles. A finales de los sesenta regresa a España, con la única intención de dirigir cine. Consigue intervenir en diversas películas y trabaja en varias ocasiones para TVE. Entre sus colaboraciones se encuentra como meritorio de dirección en las películas de Antonio Eceiza, producidas por Elías Querejeta.

En 1971 con la productora Hoy P.C18, rueda Homo Hominis. El director la firma, como también debió rotular su primer cortometraje, con su nombre y primer apellido: José Royo. Se rodó en 35 milímetros, color y con una duración de unos veinte minutos, una extensión algo menor de la duración media de los cortometrajes de la época según los datos del Ministerio de Cultura aunque en sintonía con los trabajos que producirá Hoy P.C durante esa década ${ }^{19}$.

Homo Hominis, como se deduce, apela a la celebérrima sentencia de Plauto: "Lupus est homo homini, non homo, quom qualis sit non novit". El filósofo Thomas Hobbe reutilizó la expresión para explicar como el egoísmo del ser humano y la propia esencia del hombre le impedía la libertad y le imposibilitaba para la felicidad en la sociedad. Sin embargo, este cortometraje no trata realmente del egoísmo sino del extrañamiento, de cómo las personas no consiguen relacionarse y comprender la sociedad. El héroe de la película no es egoísta o altruista sino ante todo un desconocido y un incomprendido. Al igual que el espectador, el protagonista masculino va descubriendo un mundo extraño e insólito. Nada es lógico, nada parece normal o cotidiano y así hasta los objetos domésticos se vuelven inquietantes, lejanos y dispares.

El cortometraje de Jara ni trivializa ni juzga lo humano, sino que lo observa con perplejidad. Para el autor no hay nada auténtico pero tampoco hay nada espurio sino que todo está recóndito y escondido. El carácter experimental de la pieza es, sin duda, el que la libró de las críticas y de los problemas con la censura ${ }^{20}$. Francisco Llinás ya había observado que los cortometrajes de "inspiración formal y experimental" eran los que conseguían librarse con más facilidad de los cortes y las injerencias de la censura ${ }^{21}$.

Es fácil suponer que Homo Hominis encajaba en parte con los cortometrajes de la industria española de ese período entre 1969 y $1975^{22}$. En esos años se producen las primeras obras de Iván Zulveta, Álvaro del Amo, Antonio Artero... y los trabajos independientes de Pere Portabella y Joaquín Jordá. Por lo tanto, Homos Hominis se enmarcaría en esta línea experimental y formalista.

Sin embargo, los cortometrajes más populares, más comerciales y que más rédito tuvieron de ese momento mostraban una estética y un planteamiento muy distintos, verbigracia: ¿ Qué se puede hacer con una chica? (1969) de Antonio Drove, El último día de la humanidad (1969) de Manuel Gutiérrez Aragón (1969), El espíritu del animal (1971) de Augusto Martínez Torres y Juan (1972) de Gerardo García. Estas piezas, muy largas de duración en torno a los treinta minutos o más, se comportaban como pequeños largometrajes y no se limitaban a contar una situación o una breve anécdota, sino que abordan historias complejas que bien podrían haber sido desarrolladas en obras de mayor duración: "Casi ninguna de estas películas mostraba interés por reducirse a una mera anécdota (...) duran lo que tiene que durar y si las convenciones indican que el metraje era excesivo, éste es un problema de las convenciones, no de las películas" ${ }^{23}$.

\section{La adaptación de "Niebla": Las cuatro novias de Augusto Pérez (1976)}

1975 y 1976 son dos de los años fundamentes de la Historia de España. La muerte del general Franco y el primer gobierno de Adolfo Suárez suponen e imponen un cambio fundamental en la estructura del Estado que se percibe de un modo u otro en toda la producción cultural y artística del país. No sólo representan el inicio del fin de una dictadura, sino también de toda su maquinaria funcionarial y represiva, supone la clausura de todos sus procesos administrativos y el fin de los métodos de censura. Las cuatro novias de Augusto Pérez, el primer largometraje de José Jara, se realiza precisamente en dichos años y es un excelente ejemplo del veloz proceso de cambio y transformación cultural y político.

Miguel de Unamuno se encumbra entre los mejores autores españoles de la literatura de ficción y de ensayo del siglo XX. Curiosamente, si bien, existen adaptaciones cinematográficas de casi todos sus novelas y cuentos$^{24}$, su novela más estudiada, traducida e investigada, "Niebla", sólo inspiró dos películas en la cinematografía mundial25. Tal vacío ha llevado a muchos autores a plantearse si realmente "Niebla" se puede

\footnotetext{
${ }^{18}$ Hoy P.C. fue una pequeña productora que desarrolló su actividad en los años 70. Su primer trabajado archivado por la administración fue el cortometraje de José Jara. A partir de 76 produce una serie de cortometrajes experimentales del director Antonio del Real.

${ }^{19}$ Datos del Ministerio de Cultura, consultados en la base de datos de películas clasificadas. Última consulta 22/12/2010.

${ }^{20}$ El expediente del cortometraje se conserva en la Archivo General de la Administración.

${ }^{21}$ LLINÁS, Francisco: “El cortometraje independiente: Una reivindicación”. En MEDINA, Pedro y otros: Historia del Cortometraje Español. 26 Festival de Cine de Alcalá de Henares, Alcalá de Henares, 1996. Pág. 185.

${ }^{22}$ El primero en clasificar este período del cortometraje español fue Julio Pérez Perucha en su artículo PÉREZ PERUCHA, Julio: “El retorno a la ficción" en LLINÁS, Francisco: Cortometraje independiente 1969-1975. Certamen Internacional de Cine documental y cortometraje de Bilbao, Bilbao, 1986.

${ }^{23}$ LLINÁS, Francisco: Op. Cit. Pág. 163.

${ }^{24}$ Carlos F. Heredero y Antonio Santamarina citan seis largometrajes sobre obras de Miguel de Unamuno, sobre "Niebla" sólo reconocen la obra de José Jara. HEREDERO, Carlos F. y SANTAMARÍA, Antonio: Biblioteca del cine español. Cátedra/Filmoteca Española, 2010, Madrid. Pág. 493-495.

${ }^{25}$ El profesor de la Universidad de Florida Alvarez-Castro sostiene que existen cuatro adaptaciones de Niebla. Sin embargo considera que
} 
transformar en un largometraje26. Su estructura de "nivola", como la definió el propio escritor, la convierte en obra en apariencia inadaptable. Estas dos creaciones cinematográficas se iniciaron y produjeron en los convulsos 1975 y 1976 y ambas son óperas primas: Niebla (1976) de Fernando Méndez Leite y Las cuatro novias de Augusto Pérez (1976) de José Jara.

Las dos obras ofrecen muchos puntos en común en su producción y proyecto: Los dos directores noveles no eran completamente inexpertos ya que habían realizado cortometrajes y trabajos para la televisión. Méndez Leite trabajaba como realizador en el programa de "Culturas 2" de TVE (emitido en la segunda cadena) y José Jara había realizado contenidos para la televisión pública francesa y colaboraba ocasionalmente con TVE. Además, ambos creadores se embarcan en sus proyectos después de un período de inactividad forzada: Méndez Leite había sido expulsado de TVE por participar en la Huelga de Actores de $1975^{27}$ y Jara se encontraba sin productor tras el experimento formal de Homo Hominis. Por último, ambos presentan sus ideas a productoras que han planificado unas series más amplias de adaptaciones literarias. El largometraje de Méndez Leite, rodado y montado en celuloide, era un capítulo de la serie de televisión "Los libros" y la película de José Jara era la primera de una serie de largometrajes inspirados en la literatura española que pretendía hacer la productora de Lourdes María Martínez Aronson.

Cronológicamente, la obra de Méndez Leite es la primera adaptación cinematográfica ${ }^{28}$ de la novela "Niebla", en escribirse, en rodarse, en montarse y en emitirse (que a todos los efectos se considera estreno). Desgraciadamente la historiografía ha cometido un error con esta obra y la ha fechado siempre de forma equivocada, sin embargo se rodó en 1975 y se concluyó y se exhibió en 1976, siendo a todos los efectos la primera película escrita, rodada, montada y exhibida sobre una adaptación de "Niebla".

Como hemos dicho, la ópera prima de Méndez Leite pertenecía a una serie de TVE que se llamaba "Los libros"29. Este programa emitió adaptaciones desde 1974 hasta 1977. Niebla se rodó rápidamente en tres semanas en noviembre de 1975 en Segovia, Salamanca y Madrid se retransmitió en la televisión española en 1976. Es difícil escribir sobre estas fechas sin detenerse e imaginar cómo vivió el equipo de la producción la muerte de Franco en mitad de la filmación. Casi la totalidad de los actores y el equipo de dirección acaban de participar en la Huelga de Actores de 1975 y habían perdido supuestos de trabajo por criticar abiertamente la dictadura.

Méndez Leite partía de un guion existente, escrito a principios de 1975, pero lo modificó y alteró para incluir muchas de las referencias fundamentales de su universo cinematográfico. Así, por ejemplo, la película empieza con una escena homenaje a Vértigo (1958) de Alfred Hitchcock que ni se encuentra en el guion ni, por supuesto, en la novela. La obra arranca con el personaje que interpreta a Unamuno sobre el puente romano de Salamanca. Allí el escritor observa a Augusto Pérez, un hombre normal y anodino pero se siente atraído y aprehendido por él. La melodía central de Vértigo entra en escena de forma extradiegética, y en un juego visual y musical casi posmoderno Unamuno deambula por Salamanca persiguiendo a su futuro

el The Truman Show y Stranger than Fiction son "adaptaciones involuntarias". Esta teoría interesa como metáfora, pero afirmar que The Truman Show es una adaptación resulta una exageración. Si aceptásemos que todas las películas donde hay una interpelación al creador o al autor son adaptaciones de "Niebla", encontraríamos cientos de obras en la literatura y en el cine. Aún más, como se recuerda, The Truman Show ya fue acusado no solo de adaptación, sino incluso de plagio del cortometraje español Te lo mereces (1996) de Felipe Jiménez Luna; por lo tanto, también esta obra sería una adaptación involuntaria de "Niebla".

El caso de Stranger than Fiction (2006) de Marc Foster inquieta aún más ya que en la narración de la película podríamos encontrar pasajes que se "basan" en la novela como la búsqueda del autor por parte de personaje central. Como bien aciertan el profesor Alvarez-Castro y también explicaba el crítico del país Javier Ocaña (J.O.) “Si el guionista Zach Helm ha leído Niebla sólo lo puede contestar él, pero lo cierto es que la escritura para su primer largometraje contiene no pocos paralelismos con el universo metaliterario del autor español, entre ellos la visita del personaje al hogar del autor para rogarle que no escriba el desenlace previsto para su historia de ficción que él cree real" (El País, 22 de junio de 2009).

En realidad esta polémica ya apareció en la década de los veinte del siglo XX. En Italia, la nivola "Niebla" había aparecido traducida en italiano por Gilberto Beccari en 1921 el mismo año que Luigi Pirandello estrena "Seis personajes en busca de autor". Lógicamente ambas obras comparten la temática del desvelamiento del autor y el enfrentamiento de autor-personaje pero no se considera ni se acepta como una "adaptación" de Niebla aunque las posibilidades de que Luigi Pirandelllo hubiese leído o conocido el texto de Unamuno son más que factibles.

${ }^{26}$ MAHIEU, Julián: “Las nivolas en el cine” Cuadernos hispanoamericanos 440-41, Madrid, 1987. Pág. 335-340.

Sobre otras adaptaciones cinematográficas de los libros de Unamuno en ARANZUBÍA, Asier, ZUMALDE, Imanol y ZUNZUNEGUI, Santos: “Viaje a Ítaca, el caso de las adaptaciones al cine español de dos nivolas de Unamuno".Revista Signa 19 (UNED), 2010. Pág. $213-$ 234.

${ }^{27}$ La Huelga de Actores germinó en la "asamblea de los once" el 15 diciembre de 1974 . Pero no fue hasta febrero de 1975 cuando se popularizó. La primera reivindicación de los intérpretes se centraba en el abuso de los dobles programas de teatro. Tras la primera jornada del "día sin teatro", el dos de febrero de 1975, el Sindicato Nacional del Espectáculo y también el Ministro de Relaciones Internacionales, Alejandro Fernández Soto intentan llegar a un acuerdo con los actores. Sin embargo, el fracaso de la reunión del 5 de febrero generaliza la huelga y se extiende a la TVE. En ese momento Fernando Méndez Leite se suma junto a otros realizadores a la manifestación. Al cabo de unos meses todos los huelguistas son expulsados de TVE pero serán readmitidos a finales de año.

${ }^{28}$ Tanto José Agustín Mahieu como Luis Alvarez-Castro han confundido el año de producción de estas películas por ese motivo incluyen como el primer largometraje la obra de José Jara.

${ }^{29}$ Es difícil entender cómo TVE encargó un capítulo de una serie tan costosa a un director claramente huelguista. La explicación es precisamente esa: Fernando Méndez Leite una vez que se le notificó su readmisión en el ente público se negó a colaborar en Culturas 2 y exigió participar como realizador - director de "Los libros". 
personaje del mismo modo que James Stewart espía a Kim Novak desde su automóvil por las cuestas de San Francisco. Aún más, Fernando Méndez Leite termina la escena del mismo modo que el director británico: una monja nos informa que la figura que persigue el héroe es en realidad un espectro. La música de Bernard Hermann se repite y se usa durante toda la obra como una metáfora metacinematográfica ${ }^{30}$ que se cierra al final de la pieza en el encuentro personaje - autor.

Sin atender a esta introducción y a la parte final de la obra, el resto de la cinta de Fernando Méndez Leite se basa con claridad en el original literario. Como, Alvarez-Castro observa, con acierto, tal vez el problema de esta propuesta sea que es una "adaptación fiel (tal vez demasiado)"31. Méndez Leite es un excelente adaptador, como demostró años después con su monumental La Regenta (1995). Su estilo se caracteriza por regodearse en los pequeños datos y acontecimientos para presentar y describir al protagonista de la trama. En este caso, es obvio que lo que más le interesó al director era la parte cómica del relato de Augusto Pérez y así dio más ritmo a la trama, pero perdió parte de su valor y carácter metaliterario.

En 1975, cuando la película de Méndez Leite aún no se había rodado, José Royo Jara comienza el trabajo de adaptación de la novela. La productora le ofrece libertad total para realizar el guion pero la "libertad total" se transformará ante el primer óbice en "libertad parcial". Jara sugiere un cambio transcendental: transformar a Unamuno en un director de cine ${ }^{32}$. Efectivamente esta mutación supondría una visión completamente diferente y diversa de la trama y de la historia. La propuesta del guionista, claramente, sería precursora de los programas televisivos como "Gran Hermano" y de los obras fílmicas Te lo mereces (1996) de Felipe Jiménez Luna o El show de Truman (The Truman Show, 1998) de Peter Weir. Desgraciadamente, los productores le obligaron a renunciar a estas pretensiones. José Jara termina en 1975 una primera versión del primer guion literario que titula "Niebla".

El guion de "Niebla" es enviado por la productora a la Junta Censora y esta, sin embargo carente ya de toda presión real, solo notifica y conserva el texto, que aún hoy se puede consultar en el Archivo General de Administración (AGA, Alcalá de Henares) ${ }^{33}$ y en la Biblioteca Española. El título de la película era precisamente "Niebla", no obstante en ese momento se conoce la existencia de la obra de Fernando Méndez Leite y de nuevo los productores obligan a modificar las ideas de Jara, la empresa cambian el título y bautizan la película con el extraño encabezamiento: Las cuatro novias de Augusto Pérez ${ }^{34}$.

La obra de Jara se filma en Ávila, con más recursos y días de rodaje que la pieza para televisión de Fernando Méndez Leite pero sin alcanzar el presupuesto medio de la producción española de la época. Sustituir Ávila por Salamanca no es casual, José Jara no quiere solo adaptar sino que intenta crear una película con una historia y una trama nueva. Desde el primer momento nos muestra que su personaje de Augusto Pérez nada tiene que ver con el protagonista de la novela de Unamuno, es una nueva creación o un nuevo ser. Todas las obsesiones artísticas de Jara aparecen en el personaje, el protagonista se extraña de la realidad, se siente alejado en ella y solo logra comunicarse con ella por lo sensual e incluso por lo erótico. Una de las grandes audacias del director será conseguir que Fernando Fernán Gómez interprete al personaje protagonista.

José Jara profundiza en la relación entre el héroe y la sociedad y sobre todo su implicación con lo femenino. Así desde el primer momento la presencia de la madre muerta es fundamental en el relato. Pero además, sabiamente, añade o mejor dicha manipula un personaje de la novela: el "mayordomo" que se transforma en una dueña, una mujer adulta que cuida, quiere y evidentemente desea a Augusto Pérez, el cual no corresponde ni atenderá a los desvelos y empeños de su ama de llaves. Todo lo contrario y, ahora sí al igual que el texto unamuniano, el protagonista se enamora de Eugenia y goza sexualmente con la cocinera de su casa, Rosario. Este complejo juego de amoríos, enredos, conquistas y fracasos sexuales permite comprender el extraño título del largometraje: Las cuatro novias serían la dueña de la casa, Eugenia, la cocinera y su propia madre.

Este deseo por una mujer inalcanzable (Eugenia) y la presencia de la madre muerta (tanto sensual como eróticamente) podría llevarnos a una exageración ridícula: una interpretación edípica del discurso propuesto por el autor. Como habíamos visto, los dos cortometrajes anteriores el director los firma como José Royo (es decir su nombre de pila y el apellido de su padre), el guion de esta película lo entrega al a Censura con su nombre complete: José Royo Jara y, sin embargo, la obra la firma sólo como José Jara, precisamente ocultando el apellido de su padre y dejando el de su madre. Podríamos pensar que se trata de una revelación y de que este gesto oculta un poderoso complejo edípico que le hace negar de la identidad de su padre y

\footnotetext{
${ }^{30} \mathrm{El}$ espectador actual puede sorprenderse y preguntarse cómo una película cinematográfica de escaso presupuesto pudiera costearse los derechos de la banda sonora de Vértigo. En realidad esto se debía a un acuerdo que TVE había logrado con la SGAE (Sociedad General de Autores Españoles), que permitía previo pago de un canon general, utilizar cualquier música grabada.

31 ALVAREZ-CASTRO, Luis: “De la metaficción al metacine. Cuatro adaptaciones de Niebla de Unamuno”. Hispania, Johns Hopkins University Press, Volumen 93, Mazo, 2010.

32 Entrevista realizada a José Royo Jara en la Facultad de Ciencias de la Información en diciembre de 2010.

${ }^{33}$ Se conserva con número de guion: G-647 y G-648 sede de Alcalá de Henares.

${ }_{34}$ Desgraciadamente, las referencias cruzadas y los errores y erratas de las bases de datos, tan propios del cine español, han llevado a que se confundan los títulos. Así, es fácil encontrar textos que titulan la película como "Niebla" o incluso autores que mencionan dos largometrajes distintos de José Jara: Niebla y Las cuatro novias de Augusto Pérez en SÁNCHEZ NORIEGA, José Luis: De literatura al cine. Paidós, Barcelona. 2000. Pág. 226.
} 
aceptar solo el nombre de su madre (como hace el protagonista de su película). Sin embargo, esta hipótesis no es más que una especulación sin fundamentos ya que la realidad es mucho más prosaica. Charo López, actriz de la película, le advirtió en la sala de montaje que si firmase con su nombre José Royo podría provocar las risas y chascarrillos de los espectadores malintencionados ${ }^{35}$.

La relación con el cine S y el erotismo puede también hacernos escollar en la comprensión y en el análisis de la obra. Todos los autores que la han citado o estudiado insisten en como los desnudos, las caricias y las escenas sexuales enturbian la historia original36. Sin duda, el héroe del film es, como observa Alvarez-Castro, "un Augusto Pérez pervertido y fetichista" 37 pero esta "perversidad y fetichismo" no puede compararse en absoluto con los alegres y desinhibidos desnudos del destape. Todo lo contrario, la mayoría de las secuencias eróticas que filma José Jara ya se encuentran en el libro de Unamuno y sólo escenifican y dramatizan lo escrito en la novela.

Indudablemente Jara busca su propio estilo fílmico en la puesta escena y en la planificación. Rueda con esmero y se deleita en detalles. El mismo arranque de la película nos muestra con inteligencia y cuidado al héroe que construye con paciencia un barco en el interior de una botella, lo cual es una metáfora bellísima de lo que Unamuno hacía al escribir y de lo que el mismo Jara hace como director: construir una realidad dentro de otra. Su intención de cambiar y de manipular el texto para imprimir su propio sello le lleva a elaborar un final sorprendente. A diferencia de la nivola, donde Augusto Pérez muere por mandato del escritor, en la obra de José Jara, el protagonista enloquece y sus propias obsesiones y carencias son las que le conducen a la muerte.

El director se esfuerza porque el tercer acto de la película sea complejo visual y auditivamente. Mientras Augusto Pérez se aísla en sí mismo, busca una explicación y clama a Dios para recibir una respuesta, el sonido y los planos se van distorsionado y rompiendo. La cámara y la imagen se ensucian, la continuidad y las leyes básicas del eje se incumplen y todo clasicismo en el encuadre de los planos y en los movimientos de cámara desaparece. La audacia del director es aún mayúscula y se centra sobre todo en el brillante sonido. Gracias al apoyo a los estudios de sonido del Centro de Torres-Quevedo del Centro Superior de Investigaciones Científicas (CSIC) consiguió distorsionar el audio de la escena hasta crear una atmósfera desquiciante y enloquecedora ${ }^{38}$.

Una vez concluida la posproducción de la obra la productora y la distribuidora comprueban que el largometraje no interesa al público español del momento y casi ninguna sala de cine se oferta para su lanzamiento. El mercado cinematográfico se había colapsado. Las cuatro novias de Augusto Pérez debía competir no sólo con las películas contemporáneas de ese año, sino con toda la producción que había sido prohibida y secuestrada durante cuarenta años de franquismo y ahora se autorizan de golpe ${ }^{39}$. En esas fechas se estrenaban películas tan impactantes y fundamentales como El gran dictador (The Great Dictator, 1940) de Charles Chaplin, Último tango en París (Last Tango in Paris, 1972) de Bernardo Bertolucci...

Además, la estrategia de cambiar el posible título de "Niebla" por el insólito Las cuatro novias de Augusto Pérez se mostró como un desastroso método de mercadotécnica. Los espectadores, incluso los más cultos, difícilmente reconocían en el nuevo encabezamiento una adaptación literaria. "Augusto Pérez" no evoca como "Alonso Quijano", su obra literaria sino que resulta extraño y un poco ridículo. Aún más, el título situaba de nuevo a la obra en el universo del cine $S$ que se encontraba en cartelera durante esos mismos días: Zorrita Martínez (1975) de Vicente Escrivá y Mayordomo para todo (1976) de Mariano Ozores 40.

A pesar de todos los inconvenientes y de la errónea campaña de mercadeo, la película se consiguió estrenar. Ni la Filmoteca Española ni la Base de Datos del ICAI ni la Enciclopedia del Cine español de Pascual Cebollada y Gil Rubio41 revelan una fecha de estreno. Lo cual nos podría hacer pensar que la obra no se exhibió comercialmente, esto es un error. Este vacío se debe a que los tres registros anteriores solo aceptan o puntúan como estreno las primeras fechas en las que las obras se mostraron en Madrid o Barcelona. Sin embargo, la película de José Jara se estrenó de forma menor el 29 de abril de 1976 en Sevilla y en Burgos. Participó después en festivales como "Cine español de Molins de Rei" en Cataluña en 1977. A pesar de esta primera campaña tan pequeña, la acogida de la cinta fue aceptable en púbico, ya que estuvo tres semanas en sala de estreno en Sevilla.

\footnotetext{
${ }^{35}$ Como se sabe, la inmensa mayoría de los hispanos parlantes de las dos Castillas son yeístas, no diferencian entre fonemas /y/ y /1l/. Por lo tanto, los sonidos "yo", "llo" suenan iguales y el apellido Royo se percibe como "rollo"; es decir, aburrimiento o hastío.

${ }^{36}$ MAHIEU: Op. Cit. Pág. 338.

${ }^{37}$ ALVAREZ-CASTRO, Luis: Op. Cit. Pág. 15.

${ }^{38}$ Desgraciadamente, estos sonidos se han perdido en las copias que se conservan en archivos públicos como la Videoteca de la Universidad Complutense de Madrid y en la copia en DVD de la obra editada en el 2008 por Filmax. Para consultarlo y recuperar, no la totalidad, pero sí parte del efecto hay que acudir a la bobina conservada en la Filmoteca Española.

${ }^{39}$ Los productores y distribuidores de Las cuatro novias de Augusto Pérez intentaron publicitar la película como un título que había logrado superar y burlar a los censores. Su intención se basa en que el largometraje entrase en la categoría de las obras maestras recién "liberadas". Así, en la publicidad que contrataron en la primera semana de mayo de 1976 en el diario ABC-Sevilla (edición de Andalucía) se leía: "RECIÉN SALIDA DE LA CENSURA".

${ }^{40}$ Ambas obras se exhibieron en la ciudad de Sevilla a la vez que se presentaba el largometraje de José Jara.

${ }^{41}$ CEBOLLADA, Pascual y RUBIO GIL, Luis: Cronología: enciclopedia del cine español. Ediciones del Serbal, Barcelona, 1996.
} 
La crítica juzgó severamente la obra: en el diario ABC -Sevilla-, Antón Colón realizó un comentario mordaz y provocador: "Oscila así entre una pretendida intelectualización y el simple erotismo. El protagonista no es la criatura unamuniana angustiada, en agónica lucha por sobre existir, sino un obseso sexual a veces grotesco, debatiéndose entre sus deseos eróticos y las inhibiciones de una educación rígida" 42 . Para el crítico el mayor pecado de la adaptación consistía en que el trabajo fílmico se distanciaba en exceso del texto escrito. No obstante, el propio periodista reconocía: "A veces, Jara se aproxima al espíritu de la obra como en las escenas finales -dormir, soñar, vivir, morir-, con el protagonista envuelto en su desesperada niebla mental..."43. Y este comentario del crítico es fundamental porque precisamente el final de la película es la parte que más se distancia de la novela ya que directamente no ocurre lo que sucede en la nivola ${ }^{44}$.

Los grandes aciertos de José Jara son precisamente su libertad y su capacidad de expresarse como autor en un ópera prima, con poco presupuesto y con la losa de un texto tan importante. Las cuatro novias de Augusto Pérez es una buena adaptación de "Niebla" porque no pretende reproducir cada acontecimiento, cada hecho y cada gesto, sino que capta y busca la nebulosa del texto.

Tras el estreno de la película en el festival de cine español de Molins de Rei, José Jara ruega a productores y distribuidores que estrenen la película en la capital de España. Sin embargo, ambas compañías han amortizado los gastos y no desean embarcarse en un nuevo lanzamiento. Aún más, la productora desaparecerá legalmente como empresa ese mismo año. Por lo tanto, José Jara, como tantos otros directores del cine español, se da cuenta que una vez rodado su primer largometraje se encuentra sin productora y sin posibilidad de rodar.

\section{El transexual}

José Jara había perdido cualquier esperanza de volver a trabajar de forma inmediata en el cine cuando recibe un encargo insólito. Una nueva productora, Laro films, le ofrece dirigir un proyecto absolutamente novedoso, la primera película española sobre una persona transexual. Hasta este momento la transexualidad no se había reflejado en el cine español. Como recuerda Juan Carlos Alfeo 45 , existían célebres y brillantes casos de travestismo como El extraño viaje (Fernando Fernán Gómez, 1964) y en la no menos brillante, y mucho más difícil de clasificar, Mi querida señorita (Jaime de Armiñan, 1971)46, pero nunca se había realizado una película en la que la o el protagonista perteneciese al sexo opuesto al de su cuerpo; menos aún se había filmado o planteado una escena en la que la heroína o el héroe cambiase su sexo en una operación quirúrgica. El transexual (1977) como su título indica o sugiere narra la historia de un personaje femenino nacido hombre que cambia su sexo físico masculino por el femenino, la prołagonista se siente mujer y lo vivirá así, no sólo al vestirse y al comportarse, sino que se someterá a una vaginoplastia para transformarse plenamente en mujer.

Laro films había sido creada meses antes por Juan José Daza del Castillo y tenía como presidente de la compañía al director y guionista Juan José Porto. Iniciaron sus producciones con autores importantes como Fernando Fernán Gómez que rodará Bruja, más que bruja (1977) y con jóvenes promesas como Miguel Ángel Díez que filma Pecado Mortal (1977) y el propio José Jara. Sin embargo, uno de los pilares de la empresa será Jacinto Molina, conocido como Paul Naschy. Él no sólo será el guionista de varios de los títulos, sino que protagonizará otros tantos largometrajes, dirigirá para Laro Films El huerto del francés (1977) y cuando la compañía entre en crisis financiera comprará los derechos de algunas de las películas para mantener y sostener la empresa ${ }^{47}$.

Jacinto Molina cuenta en "Memorias de un hombre lobo" que la idea de El transexual se le ocurrió del siguiente modo:

"Una noche estaba tomándome una cerveza en la barra de una sala muy especial cuando se me acercó una rubia esplendorosa - muy pintada, eso sí - y comenzó a hablarme con notable desparpajo. La invité a una copa, y charlamos amigablemente. Lisa era sorprendente culta y tenía la voz muy ronca. El humo espeso de los cigarrillos podía cortarse con un cuchillo y la música lacerante del pinchadiscos nos obligaba a alzar la voz. En

\footnotetext{
42 ABC-Sevilla (Edición de Andalucía). Domingo 2 de mayo de 1976. Página 35.

43 Ídem.

${ }^{44}$ Es de suponer que Antonio Colón quedó fascinado con la puesta en escena y la distorsión del sonido del tercer acto de la película de José Jara. Por ese motivo no percibe que sucede una trama completamente diversa a la que describe Miguel de Unamuno.

45 ALFEO ALVÁREZ, Juan Carlos: "Haciendo estudios culturales. La homosexualidad como metáfora de libertad en el cine de la Transición" en AA.VV: El cine español durante la Transición democrática (1974-1983). Academia de las Artes y las Ciencias Cinematográficas de España, Madrid, 2005.

46 El caso de mi Querida señorita es realmente interesante ya que, sin lugar a dudas, el personaje central de la película se trata de un hombre que es obligado a comportarse como mujer. Por lo tanto, hay un problema de identidad sexual pero no se debería hablar plenamente ni de travestismo ni mucho menos de transexualidad. Sus padres le han educado como mujer siendo en realidad un hombre, la trama de la película consiste precisamente en el descubrimiento de la identidad sexual masculina del protagonista que es la propia de su cuerpo.

47 RIMBAU, Esteve y TORREIRO, Casimiro: Productores en el cine español. Estado, dependencias y mercado. Cátedra/Filmoteca Española, Madrid, 2008. Pág. 229.
} 
determinado momento, me sorprendió al preguntarme si había leído algo de Restiff de la Brontone. Casualmente, sí conocía a ese escritor francés, libertino y porno, del siglo XVIII. Entonces, la chica me miró intensamente a los ojos y me pregunto Tío, ¿̇ú que buscas aquí? (...) En ese momento actuaba Paco España imitando a Lola Flores. Alguien llamó a Lisa y, pasados unos minutos, tuve que ir al servicio. Estaba todavía ante el inodoro cuando Lisa entró, se levantó la falda y comenzó a orinar. Era una travestí" 48

Jacinto Molina había acudido al Gay Club49 de Madrid porque se planteaba escribir una historia o un guion sobre la muerte de Lorena Capelli quien se había convertido en la transexual más famosa de Madrid en 1976. Su espectáculo en el Micheleta Night Club se anunciaba en la sección de "espectáculos" de todos los periódicos:

"Micheleta Night Club: presenta por primera vez en Madrid a una fabulosa supervette extraordinariamente sexy, sexy, sexy antes hizo el servicio militar, ahora es intrigantemente sexy, sexy, guapísimamente Lorena Capelli, que junto con un plantel de belleza y de magia y de dinamismo de Lorgia Jr. les ofrecemos en un ambiente distinguido y elegante" 50.

Lorena Capelli había llegado a España procedente de Brasil51, había trabajado en el Cabaret Gambrinus de Barcelona y de allí viajó a Madrid al Micheleta Night Club. Durante su estancia en España opta por someterse quirúrgicamente a un cambio de sexo. Vuela a San Francisco, California, donde se produce la castración y la vaginoplastia. Por supuesto de forma clandestina. De regreso a España sufre una serie de complicaciones y debe someterse a una segunda operación esta vez en Barcelona en la que fallece en el quirófano ${ }^{52}$. La muerte de la actriz y cabaretera supone un escándalo y pone de manifiesto la existencia de clínicas donde se realizaban dichas operaciones en España.

Jacinto Molina, Antonio Fos y Juan José Porto redactaron un guion literario basado libremente en este suceso. La historia es la de un periodista (que interpretará el propio Jacinto Molina) caído en desgraciada que prepara un reportaje sobre las operaciones ilegales de vaginoplastia en España. La idea que presentan a José Jara se acerca más a las tramas de cine policíaco y de crímenes que solía interpretar Jacinto Molina que a una historia de denuncia social o política. Sin embargo, José Jara se plantea un enfoque distinto. A diferencia de la propuesta que le ofrecen, una película convencional de investigación, él propone una segunda trama: el rodaje de una entrevista a Yeda Brown, una transexual brasileña que directamente a cámara cuenta su vida y sus experiencias. Por lo tanto, la propuesta de Jara es absolutamente novedosa no solo se trataría de la primera película de ficción sobre la transexualidad en España sino también el primer documental en profundidad a una mujer transexual.

El día 1 marzo de 1977 se realiza la fiesta de inicio de rodaje. Tanto los guionistas, como los productores, el director y los periodistas invitados piensan que será el rodaje de la primera obra sobre la transexualidad en España. "La noche loca de los travestís" es el título de la reseña de dicha fiesta que hace la reportera Pilar Trenas para el semanario Blanco y Negro en la cual se llega a afirmar que "no hay duda que hoy Madrid se ha convertido en la capital de los travestís" 53.

El casi seguro éxito de la película se empañado porque en mayo de 1977 el cine Luchana aparece cubierto con unos cartelones publicitarios de una película titulada Cambio de sexo. Mientras José Jara terminaba el rodaje de El transexual, Vicente Aranda estrenó en dicha sala el 13 de mayo su largometraje. Cambio de sexo (1977) fue, por tanto, la primera obra sobre una transexual en el cine español y se llevó todos los elogios y el éxito por tal atrevimiento.

Cambio de sexo (1977) narra de una forma lineal la evolución de un joven (interpretado por Vitoria Abril) que siente su cuerpo como mujer y no como hombre. La protagonista luchará por adaptarse a su entorno, a su colegio y a su familia no obstante esto es imposible porque ella se descubre y se siente como mujer. Su padre en un insensato y ridículo gesto de masculinidad la lleva a un club de alterne donde una prostituta debe probar la virilidad de la heroína y hacerla un hombre. La joven se queda fascinada en el club por la actuación de una mujer transexual (Bibi Andersen). La protagonista opta por vivir en Barcelona y luchar por descubrirse y vivir como mujer. Gracias a la ayuda de Bibi Andersen entra a trabajar en el cabaret y termina operándose y cambiando de sexo.

\footnotetext{
48 NASCHY, Paul: Memorias de un hombre lobo. Alberto Santos, Madrid, 1998.

${ }^{49}$ La anécdota que cuenta Paul Naschy ha sido repetida en otros textos y libros, sin embargo, contiene un error: Lorena Capelli no actuaba en el Gay Club (que se encontraba en el Paseo del Prado de Madrid) sino en Micheleta Night Club (Plaza de Santo Domingo). Quien ejercía en Gay Club era Paco España y será en ese local donde filmarán la película.

${ }_{50}$ ABC 08/10/1976. Página 82.

${ }^{51}$ Algunos autores dicen que procedía de Italia pero no es así. Lorena Capelli y Yeda Brown se conocieron en Brasil, ya que sus familias eran amigas, y viajaron juntas a España. Se puede consultar un amplio reportaje en el Blanco y Negro 17/05/1978 Pág. 38-40.

52 Existen diversas versiones de la motivos de la trágica muerte de Lorena Capelli, pero la más verosímil es la muerte en el quirófano como lo relata el Dr. José Manuel Reverte en "Transexualismo" en internet en la página del Instituto Conmemorativo Gorgas de Estudios de la Salud de Panamá.

Sin embargo, en el portal de internet de la web Carla Antonelli recogido en la página oficial del LGTB de España se presenta una entrevista en la que Mr. Arthur en mayo de 1982 sostenía que Lorena Capelli había muerto de peritonitis. (www.carlaantonelli.com/pierrot_memorias_de_transexuales, última entrada 23 de diciembre de 2010).

53 TRENAS, Pilar: "La noche loca de los travestís". Blanco y Negro. 23/3/1977. Pág. 55.
} 
La película está construida con eficacia y si bien al espectador poco acostumbrado al cine español de los setenta le puede resultar pobre en recursos o torpe en su realización, lo cierto es que una obra realizada con tacto y cuidado, alejándose de los excesos del destape imperante. Cambio de sexo tuvo una excelente acogida de público y llegó a lograr más de 800.000 espectadores ${ }^{54}$.

Tras el éxito de Cambio de Sexo, los productores de El transexual se encuentran con la dificilísima tarea de estrenar una obra sobre el mismo tema. La película se proyecta por primera vez en Barcelona el 17 de octubre y en Madrid el 4 de noviembre ${ }^{55}$. Desde se momento las críticas se ceban en que la obra carece de originalidad en el tema: "El transexual tenía una baza importante en la novedad del tema pero perdió puntos después de pisotón de Cambio de sexo"56. Y lógicamente "este pisotón" se verá reflejado en la taquilla, la obra de José Jara solo sobrepasa débilmente los 400.000 espectadores ${ }^{57}$.

El transexual no se basa en un texto literario importante, como "Niebla", ni se apoya en actores prestigiosos o relevantes como Fernando Fernán Gómez. Todo lo contrario, el proyecto nacía desde una perspectiva realmente distinta: primero originalidad y descaro en un tema no tratado en la actualidad, apoyo en actrices "sexys", como Agatha Lys, y polémicas, como Yeda Brown, pero sobre todo se basa en la figura de Jacinto Molina y su alter ego Paul Naschy. Se había planteado como una historia en el que el protagonista indiscutible era un hombre, heterosexual, que resolvía la misteriosa muerte de una transexual. José Jara consciente de la dificultad del texto decide romper la trama y la ficción de la obra.

La obra tiene tres estructuras claramente diferentes. Por un lado el documental (reportaje en profundidad) a Yeda Brown, en el cual narra en primera persona sus experiencias, nada de esto estaba en el guion original y, por supuesto, todo su texto es espontáneo y a veces, como lenguaje coloquial, torpe y sucio. La segunda estructura de la película son los números musicales. Casi todas las coreografías se basaban en números ideados por Paco España y fueron planificadas por Jara, estas actuaciones tampoco estaban en el guion literario. Por último, se encuentra la propia ficción, es decir, el texto del guion literario que es lo que menos interesa a Jara.

El director no solo narra tres historias sino que las planifica de forma completamente distinta. El documental sobre Yeda se plantea intimista y cercano, las piezas musicales se realizan con modernidad y osadía (próximas a lo que había sido Cabaret [1972] de Bob Fosse). Y, por último, la trama de ficción se rueda en el estilo propio de las películas detectivescas de Paul Naschy. La mezcla de los tres estilos hace que la obra resulte original e insólita.

El transexual es una obra citada y comentada pero siempre desde dos ópticas. La primera vía es lógicamente la de género, la segunda es la de los trabajos sobre Paul Naschy. Por ello a todos los autores les cuesta situar la obra. Así, Alberto Mira sostiene:

"a esto añade las intervenciones de Yeda Brown, una transexual que habla directamente a cámara sobre los detalles del cambio de sexo y cuyos parlamentos parecen escritos por Ed Wood. La mezcla de aspiraciones científicas con la trama periodística produce momentos de hilaridad (como cuando nuestra cicerone nos asegura sin la menor ironía que de pequeña los médicos le aseguraron que tenía "demasiado cromosomas femeninos")" 58.

Es cierto que Yeda Brown, como cualquier hablante del español como segunda lengua, comete errores lingüísticos y torpezas, en sus diálogos pero precisamente en su texto inhábil, que denota la escasa formación académica de esta mujer transexual, reside la verdad y la grandeza de su testimonio, absolutamente espontáneo, sin escritura previa y que se manifiesta en su drama con total libertad y dureza. Completamente opuestas son las críticas que provienen de los estudios $u$ homenajes a Paul Nachy. En ese caso los autores sostienen que la obra es tan "original" que no parece una película del actor.

Muchos de los textos que analizan la obra confunden la autoría del film. Así Albero Mira y Laurentino Vélez-Pelligrini consideran que el director es José Lara, como hemos visto sustituir Lara por Jara podría ser una errata repetida de capítulo a capítulo y de libro a libro pero también podría deberse a una confusión con el doctor en medicina José Lara. Aún más, en esta confusión y baile de erratas sobre la dirección del largometraje, otros investigadores y críticos incluso consideran que la obra es codirigida entre José Jara y León Klimovsky. Lo cual, huelga decir, es falso.

La crítica más dura de la película se encuentra precisamente en la mirada hacia lo transexual. Y lo encontramos en el propio título El transexual: parece lógico que debía titularse La transexual. Todo en la cinta tiene un mirada inequívocamente bienintencionada pero "transfóbica" como bien escribe Alberto Mira, sobre esta película y sobre Cambio de sexo: "De alguna manera los tratamientos sobre travestis inciden siempre en lo anormal para dar al espectador heterosexista una posición privilegiada: por una parte se le pide

\footnotetext{
54 Datos del Ministerio de Cultura: 840.621 espectadores. fechas en la hemeroteca de diario ABC 5/10/1977.

56 HERMES: “El transexual”. 05/07/1977, ABC, Pág. 59.

57 Datos del Ministerio de Cultura: 419.400 espectadores.

58 MIRA, Alberto: Miradas insumisas. Gays y lesbianas en el cine. Egelas editorial, Barcelona, 2004. Pág. 410.
}

55 Una vez más, los registros del Ministerio de Cultura y las fichas del ICAI contienen errores y fallos. Ya que el estreno se produce en Barcelona el 17 de octubre en el Petit Pelayo, sin embargo esta fecha no aparece en ningún documento oficial del Ministerio. Para confirmar el evento hay que recurrir al periódico catalán La Vanguardia 16/09/1977 y 17/09/1977. Del mismo modo el estreno en Madrid se produce el día 4 de noviembre y no el día 16 de noviembre como figura en la ficha del Ministerio, se puede comprobar estas 
comprensión pero por otra se impide toda identificación"59. En la misma línea se manifiesta Laurentino VélezPelligrini "A pesar de presumir de corrección política, El transexual abarca el tema desde una óptica heteronormativa y, por tanto, con unos ramalazos homófobos"60.

Tanto Cambio de sexo como El Transexual han sido y son dos películas polémicas: En los años setenta lo fueron porque se enfrentaron a uno de los tabús de la sociedad y, en la actualidad, lo son porque el retrato que hacen de las transexuales resulta retrógrado y denigrante. Juan Carlos Alfeo ${ }^{61}$ ha abordado con acierto un tema diverso pero que puede ayudarnos a entender la transexualidad62 en el cine español. Sus investigaciones se centran en cómo el cine español ha retratado al homosexual. Su obra revela el itinerario que han seguido las obras y cómo el perfil del homosexual ha ido cambiando desde la visión de un hombre pervertido y asociado al drama y la nocturnidad hacia la imagen de un hombre integrado y pleno en la sociedad. Esta claro que ni Cambio de sexo ni El transexual deben ser entendidas como películas sobre la homosexualidad ya que sus dos protagonistas son claramente mujeres transexuales de orientación heterosexual; cierto es que algo parecido a lo expuesto por Juan Carlos Alfeo se puede encontrar al analizar en la transexualidad en el cine español. Las dos primeras películas son claramente rompedoras y polémicas con los tabús, pero a la vez muestran una visión denigrante de las transexuales que sólo pueden sufrir, mutilarse y ocuparse en el quehacer de cabareteras o prostitutas.

Lo interesante de El transexual es precisamente esa ruptura de códigos y ese posicionamiento en el límite entre los géneros cinematográficos: No es un documental, no es una película de ficción sobre las y los transexuales, tampoco es sólo una película de Paul Naschy sino una obra plenamente posmoderna que mezcla y combina estilos y formas.

\section{4. "Mater Amantissima" y El oasis de las chicas perdidas}

Harto del mundo cinematográfico, José Jara se enfrenta a una crisis artística. Su trabajo como director no sé reconoce y él mismo como creador no se siente apoyado o defendido por ninguno de sus productores. Aunque sus dos primeros largometrajes han conseguido estrenarse y el segundo de ellos ha sido un éxito comercial, ningún empresario le ofrece otro trabajo o acepta alguna de sus sugerencias. Antonio Lara, profesor de la Universidad Complutense, decía que "hacer una película en España es, frecuentemente, tan duro como luchar en un campo de batalla y, a veces, aún más"63; efectivamente, Jara en 1979 se encontraba en mitad de esa contienda.

En el verano de ese año, José Royo decide distanciarse de la industria y del entorno del cine. Busca un nuevo reto y se arriesga a escribir una novela erótica para presentar al concurso la Sonrisa Vertical, organizado y dirigido por Luis García Berlanga. Su propuesta es enviar un texto breve y conseguir publicarlo en una de las editoriales más prestigiosas del país: Tusquets. La Sonrisa Vertical como muestra Pedro López Martínez ${ }^{64}$ no era sólo una colección más sino el referente de la literatura erótica española en el último cuarto del siglo XX.

José Jara redacta "Mater amantissima" que narra una historia de despertar sexual de un niño adolescente mas este no se debe entender como un dulce y acaramelado cuento de maduración personal tan propio del cine español, sino de una verdadera trama pornográfica. La novela comienza con la muerte de la madre del héroe, como había empezado su primer largometraje, pero en este caso el niño acude al velatorio y es allí donde se inicia en la sexualidad. En el texto aparece la coprofagia, necrofilia, el sadismo, el masoquismo... se trata de un texto alejado del erotismo remilgado o edulcorado y se encauza en el universo de la pornografía de George Bataille y del Marqués de Sade 65.

Jara presenta la novela a la segunda convocatoria del concurso de la editorial Tusquets y logra un accésit que le posibilita su publicación. Ese año el ganador será "Deu pometes té el poner" de un autor colectivo que firmó con el seudónimo Ofelia Dracs. En 1980 se imprime el libro de Jara con el número 22 de la colección Sonrisa Vertical. Una vez más las coincidencias y el azar castigan a José Jara y ese mismo año se

${ }^{59}$ MIRA, Alberto: Op. Cit. Pág. 411.

${ }^{60}$ VÉLEZ-PELLEGRINI, Lauretino: Minorías sexuales y sociología de la diferencia. Gays, lesbianas y transexuales ante el debate identitario. Motensinos, Barcelona, 2008. Pág. 402.

${ }^{61}$ ALFEO ALVÁREZ, Juan Carlos: La imagen del personaje homosexual masculino como protagonista en la cinematografía española. Servicio de publicaciones de la UCM, Madrid. 2003.

62 Aunque la transexualidad se ha asociado en el pasado a la homosexualidad y al travestismo, estos son dos errores habituales. Una persona transexual no tiene por qué ser ni homosexual ni travesti. Países con severas y restrictivas leyes contra la homosexualidad autorizan, sin embargo, la transexualidad (Irán).

Por supuesto, muchos transexuales junto a lesbianas, homosexuales, bisexuales, pansexuales e intersexuales ante las discriminaciones que sufren se han constituido en asociaciones para defender sus derechos. A estas agrupaciones se las conoce con el acrónimo LGTBQ.

${ }^{63}$ LARA, Antonio: "Canciones para después de una guerra". Revista de Occidente, número 53. Pág. 92. Tomado del GARCÍA FERNÁNDEZ, Emilio C. (Coordinador): Antonio Lara, la enseñanza de la imagen. Departamento de Comunicación Audiovisual y Pubicidad 1, Madrid, 2009.

${ }^{64}$ LÓPEZ MARTÍNEZ, Pedro: La Sonrisa Vertical: Una aproximación crítica a la novela erótica española. Universidad de Murcia, Murcia. 2007.

${ }^{65}$ No en balde José Royo Jara dirige la tesis doctoral de Manuel López Villegas: "Presencia del Marqués de Sade en la obra cinematográfica de Luis Buñuel". Leída en la Facultad de Ciencias de la Información el 21 de abril de 1997. 
estrena una película con el mismo título, con una "s" de diferencia, Mater amantísima (1980) de J.A. Salgot que nada tiene que ver con el texto escrito.

Tras la publicación de la novela "Mater amantissima" recibe un peculiar y estrambótico encargo de la productora española J.E. Films y de su compañía socia francesa Eurocinè. J.E. Films era una pequeña empresa que acababa de rodar Euginie (Historia de una perversión) (1980) de Jesús Franco y que pretendía consolidar una alianza con la enorme Eurocinè, que para entonces ya había realizado algunas de las películas claves del cine erótico, "trash" y de terror de toda Europa. J. E. Films, fundada por Julián Esteban (sus iniciales forman la sigla J.E.), se creó y se registró como una empresa individual para la producción de películas. Esteve Rimbau y Casimiro Torreiro cifran la producción total de la empresa en 6 largometrajes rodados todos entre 1980 y 198166.

J.E. Films se sustentaba, apoyaba y en cierto modo emulaba el sistema de producción de Eurocinè que era complejísimo y vastísimo; baste como ejemplo que sólo en España la compañía gala logró coproducir y estrenar más de veinte títulos entre 1970-1985. Su temática era el erotismo S, la violencia sexual, el rapto, las torturas y las perversiones mezclando todo con elementos de terror, asesinatos, crímenes y violencia. Uno de los españoles que más colaboró con la empresa francesa fue Jesús, o Jess, Franco que rodó con ellos una decena de títulos. Pero también trabajaron otros directos más "prestigiosos" o "reconocidos" como lgnacio F. Iquino o Juan Fortuny.

Eurocinè era una productora extraña y pasmosa. Aún hoy resulta difícil clasificarla y encasillarla no sólo por su temática sino también por el estilo y la narración de sus películas. La mayoría de sus obras camina sobre un delgadísimo hilo argumental, casi inexistente, que se basa más en la tensión sexual, en los momentos eróticos y en las acciones violentas que en la historia que cuenta. Los sucesos que acontecen en sus narraciones resultan muchas veces inconexos e, incluso, ilógicos. Además, Eurocinè producía con escasos e ínfimos presupuestos lo que provocaba que algunas escenas se rodasen de forma célere y con torpeza. Pero sin duda el mayor problema para la verosimilitud de sus obras era que la empresa en un alocado criterio de abaratamiento de precios reutilizaba con frecuencia distintos planos, escenas o secuencias enteras rodadas para filmes diversos.

Resulta fácil entender por qué Eurocinè y J.E. Films se fijaron en José Jara: autor de dos largometrajes con elementos eróticos, escritor de la colección "la Sonrisa Vertical" y realizador de largometrajes con modestos presupuestos, también se comprende por qué Jara aceptó trabajar con ellos ya que carecía de una compañía que le produjese otro film. Sin embargo, el director lamentará rápidamente su decisión de aceptar el encargo, ya que la escasa libertad que había logrado conseguir en sus dos primeros títulos cinematográficos se volvió en este caso en servidumbre total hacia los métodos de las productoras.

El guion pertenecía a Julián Esteban, que entre el 1980 y 1983 escribirá más de una decena de largometrajes, a veces los firmará con su nombre y en otras ocasiones utilizó su seudónimo Julius Valery. Toda su obra se caracteriza por el uso del erotismo y del terror y la combinación de ambos en un duelo de pesadilla sexual. Después de leer el guion, José Jara pensó que podría "reescribirlo" como hizo con El transexual. Sin embargo, esta vez el guionista-productor le impidió cualquier cambio sustancial en la trama y en el esquema de la obra.

La producción se realizó en España, aunque se insertan imágenes de desfiles y paseos rodados para otros proyectos en la ciudad de París. Se escogió la provincia de Alicante para filmar los exteriores. Los desacuerdos entre los productores y el director se mantuvieron durante toda la filmación y antes de terminar el rodaje el director se retiró del proyecto y exigió firmar la obra con un seudónimo, John O’Hara (pronunciado en español: Oh, Jara). Los productores montaron la película, incluyeron, como era habitual en Eurocinè, fragmentos de otras obras y terminaron estrenándola el uno de junio de 1982.

El oasis de las chicas perdidas narra una inconexa, y a ratos incomprensible, historia sobre una trata de blancas. Dos jóvenes parisinas son seducidas por unos hombres desalmados que las envenenan, las secuestran, las violan y las envían a una isla perdida cercana al continente africano. Allí las chicas francesas son obligadas a prostituirse en un burdel junto a otras mujeres de Europa y África que también han sido víctimas de rapiñas. Un detective privado descubre el lugar, consigue liberar a las secuestradas y perseguir a los canallas.

El estilo de la película, la precariedad del rodaje, la inexistencia de decorados y lo inapropiado de los exteriores naturales, amén de la falta casi total de recursos técnicos y de atrezo transforman el largometraje en un auténtico simulacro irreal e inverosímil. La reacción de los personajes, los acontecimientos y los hechos se suceden sin que el espectador entienda, se emocione o pueda seguir con claridad la trama. Además los fragmentos añadidos para incluir espectacularidad y erotismo resultan extraños, torpes e incomprensibles.

El oasis de las chicas perdidas es, sin duda, el único largometraje de José Jara donde no se encuentra nada de su propio estilo, de su propia mirada o de su forma de entender el mundo. Es una película insólita, extravagante y pobre que muestra ejemplarmente en lo que se transformó la producción de obras $S$ en España. A pesar de la singularidad de la obra, la escala o nula publicidad, que se dio a la misma, se lograron más de 65.000 espectadores.

${ }_{66}$ RIMBAU, Esteve y TORREIRO, Casimiro: Op. Cit.Pág. 278-279. 


\section{La última etapa: el cortometraje industrial}

Tras el fracaso artístico de El oasis de las chicas perdidas, José Royo Jara siguió intentando rodar y filmar proyectos. Los rechazos de la producción hacia sus sugerencias de ficción le obligaron a probar suerte en la producción del cortometraje industrial. El cine industrial es, sin lugar a dudas, (como observan Emilio C. García Fernández y Rafael Gómez ${ }^{67}$ ) el gran desconocido de la Historia del Cine. Su análisis se encuentra fuera de los manuales, de las historias regladas y de los anuarios de cine. Aunque muchas filmotecas, entre las que se encuentra afortunadamente Filmoteca Española, han conservado y se han molestado en catalogarlas lo cierto es que la investigación realizada es exponencialmente menor que la que se encuentra en el cine de ficción. Adentrarse o intentar situar los trabajos industriales de José Jara dentro de un "panorama" contemporáneo resulta complejo y difícil. Sin embargo, según los pocos datos conocidos que tenemos, José Jara fue uno de los directores de cine industrial más prolíficos en el año 1983 (así lo recoge Medardo Amor68 quien marca sus trabajos para la empresa Majesa como uno de los más estables del panorama).

Majesa era una productora que había comenzado a filmar obras cinematográficas en 1979, pero que tras realizar dos cortometrajes de Jesús Sastre no concluyó ningún otro proyecto hasta el 1983. Ese año encarga a José Royo Jara que realice seis documentales publicitarios e industriales sobre la ciudad de Madrid y el medio ambiente. En todas ellas la presencia de Jesús Sastre será fundamental ya que ejercerá de operador jefe y de montador.

Las seis piezas presentan la misma estructura: una narración en voz en off que explica a modo de narrador alguna de las características de la urbe o de la ecología, especialmente se realizan tres obras sobre las aguas y los ríos. Con un tono ameno se cuenta y se promociona el trabajo del Ayuntamiento. Las obras tienen un acabado correcto y una estructura clásica nada comparable al estilo rupturista de sus trabajos de ficción.

Las seis obras son las siguientes: Madrid, aguas claras (1983); Madrid, aire sano (1983); Madrid, limpio (1983); Madrid, verde (1983); El agua, potabilización (1983) y El agua, depuración (1983). La mayoría de las obras se filmaron con el mismo equipo que lo formaban en la dirección José Jara; como argumento y guion Manuel Torre Iglesias y José Jara; como operador y montador Jesús Sastre; como ayudante de dirección Lucio Blanco y como narrador José María del Río69.

A diferencia de lo que ocurrió con otros productores de cine industrial, como Cinecorto del también profesor de la Universidad Complutense, Luis Enrique Torán, la productora Majesa (a pesar de producir seis obras en un solo año) fue incapaz de realizar más proyectos audiovisuales. Cuando Emilio C. García Fernández y Rafael Gómez analizaron Cinecorto descubrieron que una de las grandes virtudes de dicha empresa había sido su diversificación, "debía atender a todos los sectores"70. El gran problema de Majesa fue precisamente centrarse sólo en los trabajos de un sector y un cliente potencial: el Ayuntamiento de Madrid.

\section{Profesor: apocalípticos o integrados}

José Royo Jara regresa de nuevo a la Universidad Complutense, con su experiencia como director de tres largometrajes, con estudios de postgrado en el extranjero y con los cursos de doctorado realizados en IHUC se presenta y gana una plaza de profesor de Dirección Cinematográfica en la Facultad de Ciencias de la Información. Aunque su idea es compaginar los trabajos como docente y las prácticas en la profesión, los cortometrajes industriales los filmó ya cuando era enseñante, pronto desiste de este doble empeño y se centra en su labor docente.

Redacta, bajo la tutela de Manuel Gitrama, su tesis doctoral "El derecho a la propia imagen de los intérpretes cinematográficos con referencia a la Ley Orgánica del 5 de mayo de 1982". Partiendo de dicho trabajo, José Royo Jara publicará en la prestigiosa colección de textos de Derecho Colex, un libro titulado: "La protección del derecho a la propia imagen"71. Aunque José Jara había realizado un carrera artística e intencionadamente se había alejado y distanciado del Derecho su tesis doctoral era un obra sobre ciencia jurídica aunque desde un enfoque claramente artístico y por lo tanto novedoso ${ }^{72}$.

\footnotetext{
${ }^{67}$ GARCÍA FERNÁNDEZ, Emilio C. y GÓMEZ, RAFAEL: “Un aportación al cine industrial” en GARCÍA FERNÁNDEZ, Emilio C. (Coordinador): Torán, escritor de luz. Departamento de Comunicación Audiovisual y Publicidad 1, Madrid, 2004. Pág. 99.

68 AMOR, Menardo: “Desde finales de los setenta hasta los años noventa" en MEDINA, Pedro; GONZÁLEZ, Luis Mariano y MARTíN VELÁZQUEZ, José (Coordinadores): Historia del cortometraje español. Festival de Cine de Alcalá de Henares, Alcalá de Henares, 1996.

${ }^{69}$ Las fichas que ofrece el Ministerio de Cultura de estas obras en su base de datos de películas clasificadas, como ocurre con frecuencia, comenten algunos errores y erratas graves. Para consultar al equipo de las mismas hemos cotejado las fichas del MCU, los títulos de créditos de las películas y entrevistado a José Royo Jara. Además, alguna de estas obras se pueden encontrar en programas de descargas online con fichas de crédito que contienen los errores y las erratas del Ministerio de Cultura, sirva de ejemplo: www.mundocine.net/Madrid-aguas-claras-pelicula-31648.htmlv (consultado última vez 26 de noviembre de 2010).

${ }^{70}$ GARCÍA FERNÁNDEZ, Emilio C. y GÓMEZ, Rafael: Op. Cit. pág. 100.

${ }^{71}$ La Editorial Colex era una de las colecciones más prestigiosas del Derecho, publicado como ROYO JARA, José: La protección del derecho a la propia imagen. Colex, Madrid, 1987.

${ }_{72}$ La Editorial Colex presentó una Nota de la Editorial en la cual explicaba los motivos de la publicación, en los cuales los editores se "enorgullecían" del proyecto y manifestaban la singularidad del trabajo al tratarse de un creador audiovisual y un jurista al mismo
} 
José Royo Jara se encarga de impartir varias asignaturas entre ellas: Videoarte y Cine Experimental y Dirección Cinematográfica. Uno de los temas capitales centrales de sus clases y de su enseñanza se centraba en la polaridad entre "integrado" o "apocalíptico". José Jara se inspiraba en la célebre dicotomía de Umberto Eco "apocalittici e integrati"73 y consideraba que el artista se debía posicionar en el mundo y en la sociedad. El integrado era aquel que seguía la corriente de las modas y las obras. Un artista integrado sería quien sabía escoger a que otros creadores imitar, copiar o emular. Si bien su éxito comercial o popular no estaba asegurado sí sabía que evitaba el fracaso mayúsculo. El apocalíptico era, por supuesto, aquel que se arriesgaba en los temas, en las formas y en las estéticas pero también el que estaba dispuesto a realizar sus ideas a cualquier precio y con cualquier medio. Del mismo modo que a los integrados nadie garantizaba su éxito pero a diferencia de ellos, los apocalípticos, como funambulistas, andaban al borde de la incomprensión y del rechazo absoluto. Ni que decir tiene, que José Jara fue a todas luces un ejemplo paradigmático de autor apocalíptico.

Muchas de sus últimas propuestas didácticas y de los ejercicios que proponía a sus alumnos, como el intercambio de memorias y de conversaciones, podrían analizarse dentro del llamado arte relacional de Bourriaud ${ }^{74}$. De una forma significativa, en su metodología docente, José Jara insistía en la influencia del cuerpo como elemento artístico en el videoarte actual. Jara se inspiraba no solo en los textos de otros pensadores franceses, especialmente Jacques Derrida y Jean-Luc Nancy. Así, una de las prácticas obligatorias para aprobar consistía en que cada estudiante debía de-construir su vida y su memoria, acercándose al concepto de tras-humano que se desprende de la filosofía de $\mathrm{Nancy}^{75}$.

José Royo Jara en absoluto se mantuvo aislado de la creación artística en sus últimos años. Alejado de cualquier centro de poder, de creación o de movimiento estético, realizó y realiza durante los últimos años de su vida una carrera de escultor. Fiel a su espíritu ácrata y libre diseñó y fabricó esculturas en su vivienda. Esta última forma de expresión, como ocurrió, en su carrera audiovisual no se dirigían ni a los mercados ni a las ferias, ni a los museos, ni a las galerías sino que las esculpió, y las esculpe, como un acto libérrimo apartado de los eventos y cauces habituales del arte actual. Su estilo escultórico, cuyo profundo análisis se encuentra fuera de este trabajo, se centra y se inspira en el arte povera de los sesenta y del ready-made ${ }^{76}$.

\section{Conclusión}

José Jara presenta un perfil único de director de cine en la industria española. Su trabajo cinematográfico resulta novedoso y original por su temática (la adaptación de "Niebla", la transexualidad...), por su puesta en escena y por su carácter posmoderno y rupturista. Sin embargo, precisamente su distanciamiento y su alejamiento de la estética dominante, de los centros de poder y de las productoras le transformaron en un cineasta insólito y por ello tuvo que abandonar la creación audiovisual.

Las cuatro novias de Augusto Pérez es la única adaptación cinematográfica realizada para ser exhibida en salas de cine hasta la fecha. Su valor artístico es grande no solo por abordar un texto tan complejo como el de Miguel de Unamuno, sino también por la acertada propuesta que ofrece su director.

Del mismo modo El transexual es un largometraje de una gran originalidad. No es la primera película española que aborda la transexualidad, pero su puesta en escena es brillante. El incluir la entrevista realizada a una mujer transexual aumenta en credibilidad y transforma la obra en un producto audiovisual más complejo. En este film se mezcla la ficción y la no ficción en un juego posmoderno.

Su novela "Mater Amatíssima" y su película El oasis de las chicas perdidas representan un acercamiento a la literatura y el cine eróticos. El autor plantea en estas dos creaciones artísticas una visión descarnada y apasionada de la sexualidad. La productora intervino en la dirección de este último largometraje y por ese motivo resulta difícil saber cuáles son los aciertos y defectos de José Jara en dicho trabajo.

Siguiendo las propias definiciones del autor, José Jara es un ejemplo paradigmático de un creador apocalíptico que por hacer cine aceptó trabajar en las peores condiciones, con las peores posibilidades y los recursos más ínfimos. No deja de ser sorprendente que un profesional autodidacta e independiente terminase encontrando su santuario artístico en la universidad, enseñando dirección cinematográfica y videocreación. Al final José Royo Jara se convirtió en un artista apocalíptico refugiado en la universidad.

\section{Bibliografía citada}

ALFEO ALVÁREZ, Juan Carlos: La imagen del personaje homosexual masculino como protagonista en la cinematografía española. Servicio de publicaciones de la UCM, Madrid. 2003.

tiempo.

${ }_{73}$ ECO, Umberto: Apocalittici e integrati. Comunicazioni di massa e teorice della cultura di massa. Milano, Tascanili Bompiani, 2005.

${ }^{74}$ BOURRIAD, Nicolas: Estética relacional. Buenos Aires, Adriana Hidalgo, 2008.

75 Conferencia ofrecida el jueves 6 de octubre en el CENDEAC por el investigador Jordi Massó (UCM): “El cuerpo ontológico y el arte transhumano: una lectura de la filosofía de Jean-Luc Nancy".

${ }^{76}$ La mayoría de sus piezas se reconstruyen con objetos encontrados y materiales industriales y de construcción desechados. Aunque se basa indudablemente en las obras de Marcel Duchamp se acercan a las piezas del británico Tony Cragg o de la última etapa de Gary Kuehn. 
ALVAREZ-CASTRO, LUis: "De la metaficción al metacine. Cuatro adaptaciones de Niebla de Unamuno". Hispania, Johns Hopkins University Press, Volumen 93, Mazo, 2010.

ARA, Pedro: El caso de Eva Perón. CVS ediciones, Madrid, 1974.

ARANZUBÍA, Asier, ZUMALDE, Imanol y ZUNZUNEGUI, Santos: "Viaje a Ítaca, el caso de las adaptaciones al cine español de dos nivolas de Unamuno". Revista Signa 19 (UNED), 2010.

AA.VV: El cine español durante la Transición democrática (1974-1983). Academia de las Artes y las Ciencias Cinematográficas de España, Madrid, 2005.

BORDWELL, David, STAIGER, Janet y THOMPSON, Kristin: El cine clásico de Hollywood. Paidós, Barcelona, 1997.

BOURRIAD, Nicolas: Estética relacional. Adriana Hidalgo, Buenos Aires, 2008.

CEBOlLADA, Pascual y RUBIO GIL, Luis: Cronología: enciclopedia del cine español. Ediciones del Serbal, Barcelona, 1996.

ECO, Umberto: Apocalittici e integrati. Comunicazioni di massa e teorice della cultura di massa. Milano, Tascanili Bompiani, 2005.

GARCÍA FERNÁNDEZ, Emiio C. (Coordinador): Antonio Lara, la enseñanza de la imagen. Departamento de Comunicación Audiovisual y Pubicidad 1, Madrid, 2009.

GARCÍA FERNÁNDEZ, Emilio C. (Coordinador): Historial del Cine. Fragua, Madrid, 2010.

GARCÍA FERNÁNDEZ, Emilio C. (Coordinador): Memoria viva del cine español. Cuerdos de la Academia, Madrid, 1998.

GARCÍA FERNÁNDEZ, Emilio C. (Coordinador): Torán, escritor de luz. Departamento de Comunicación Audiovisual y Publicidad 1, Madrid, 2004.

GREGORI, Antonio: El cine español según sus directores. Cátedra, Madrid, 2009.

HERNÁNDEZ LES, Juan y GATO, Miguel: El cine de autor. Castellote Editor, Madrid, 1978.

JARA, José: Mater Amantíssima. Sonrisa Vertical, Tusquets Editores, Barcelona, 1980.

LLINÁS, Francisco: Cortometraje independiente 1969-1975. Certamen Internacional de Cine documental y cortometraje de Bilbao, Bilbao, 1986.

LÓPEZ MARTíNEZ, Pedro: La Sonrisa Vertical: Una aproximación crítica a la novela erótica española. Universidad de Murcia, Murcia. 2007.

MAHIEU, Julián: "Las nivolas en el cine" Cuadernos hispanoamericanos 440-41, Madrid, 1987.

MEDINA, Pedro; GONZÁLEZ, Luis Mariano y MARTíN VELÁZQUEZ, José (Coordinadores): Historia del cortometraje español. Festival de Cine de Alcalá de Henares, Alcalá de Henares, 1996.

MIRA, Alberto: Miradas insumisas. Gays y lesbianas en el cine. Egelas editorial, Barcelona, 2004.

NASCHY, Paul: Memorias de un hombre lobo. Alberto Santos, Madrid, 1998.

RIMBAU, Esteve y TORREIRO, Casimiro: Productores en el cine español. Estado, dependencias y mercado. Cátedra/Filmoteca Española, Madrid, 2008.

ROYO JARA, José: La protección del derecho a la propia imagen. Colex, Madrid, 1987.

VÉLEZ-PELLEGRINI, Lauretino: Minorías sexuales y sociología de la diferencia. Gays, lesbianas y transexuales ante el debate identitario. Motensinos, Barcelona, 2008.

\section{Hemerografía citada}

Diario ABC (Edición Sevilla y Edición La Vanguardia).

Semanario Blanco/Negro.

Diario de Burgos.

Diario El País.

Diario La Vanguardia.

Journal de Genève.

\section{Películas y archivos consultados}

Archivo General de la Administración:

Las cuatro novias de Augusto Pérez. Número de expediente: 81452. Signatura: 36/05186. Fecha reconocible y formación: 1975 / 1975.

Cambio de sexo. Número de expediente: 86597. Signatura: 36/05213. Fecha reconocible y formación: 1974 / 1976. -Se le suma el expediente de "Una historia clínica".

El transexual. Número de expediente: 90151. Signatura: 36/0523. Fecha reconocible y formación: 1976 / 1976.

Archivo Filmoteca Española:

Guion original de "Niebla" (versiones primera y segunda de Las cuatro novias de Augusto Pérez) firmado por José Royo Jara. Referencia: GUIONES-Alcalá de Henares. Número: G-647 y G-648.

Guion original de Cambio de sexo (versiones primera y segunda) firmado por Vicente Aranda y Joaquín Jordá. Referencia: GUIONES-Alcalá de Henares. Números: G-4748 y G-4966. 